\title{
Association between Fat Mass and Obesity Associated (FTO) Gene Polymorphism (rs9939609) and Polycystic Ovary Syndrome (PCOS): A Sri Lankan Study
}

\author{
Branavan Umayal $^{1}$, Muneeswaran Kajan ${ }^{2}$, N.V. Chandrasekharan ${ }^{2}$, W.S.S. Wijesundera ${ }^{3}$ and \\ Chandrika N.Wijeyaratne* ${ }^{1}$ \\ ${ }^{1}$ Department of Obstetrics and Gynecology, Faculty of Medicine, University of Colombo, Sri Lanka \\ ${ }^{2}$ Department of Chemistry, Faculty of Science, University of Colombo, Sri Lanka; \\ ${ }^{3}$ Deaprtment of Biochemistry and Molecular Biology, Faculty of Medicine, \\ University of Colombo, Sri Lanka. \\ (e-mail - mandika59@hotmail.com)
}

\begin{abstract}
Objective: to study the association of FTO gene rs9939609 variant in Sri Lankan women with PCOS. Method: Consecutive women with PCOS $(n=55)$ and controls $(n=110)$ were recruited. Clinical parameters, anthropometry and biochemistry were measured in all. DNA was extracted and tetra ARMS PCR was carried out for genotyping. The association between rs 9939609 variant of FTO gene and PCOS susceptibility was examined.

Results: High frequency of A allele was observed in PCOS group. The frequency of T allele (normal allele) was significantly higher in controls (PCOS - AA=40\%, AT=23.6\%, TT=36.3\%; Controls $A A=13.6 \%$, $A T=20.9 \%, T T=65.4 \%$ ). Significant correlation has been found between FTO gene and BMI (chi square value $=$ $17.05, p<0.05)$.

Conclusion: The rs 9939609 variant of FTO gene is associated with PCOS susceptibility in Sri Lankan women, probably because of its effect on body mass index (BMI).
\end{abstract}

Keywords: Fatty mass and obesity associated (FTO) gene, Poly Cystic Ovary Syndrome (PCOS), Body Mass Index (BMI)

\section{Introduction}

Polycystic ovary syndrome (PCOS) is the commonest endocrine disorder in women of reproductive age (Balen et al., 1995). Diagnosis of PCOS is based on the 'Rotterdam criteria', which require the presence of two of the three following features: polycystic ovaries, anovulation and androgen excess (clinical and or biochemical). Genome-wide association study identified the fat mass and obesity-associated (FTO) gene as an obesity susceptibility gene (Frayling et al., 2007). The human FTO gene is located on chromosome 16 and expressed in a wide range of tissues, including the adipose tissue and specific areas of the brain and muscles, suggesting its potential role in body weight regulation (Wehr et al., 2010). Several single nucleotide polymorphisms (SNP) of the FTO gene have been described. The variant FTO rs9939609 is the most extensively studied, located within the first FTO intron which has two alleles, A and T, the former has been linked to an increased risk for both obesity and type 2 diabetes mellitus (De Luis et al., 2013).

Given the high prevalence of obesity in women with PCOS, we hypothesized obesity susceptibility gene may play an important role in the development of PCOS. In this study, we aimed to identify the association of FTO gene variant rs9939609 with PCOS susceptibility in Sri Lankan women with PCOS. 


\section{Materials and Methods}

The study was approved by the Ethical Review Committee, Faculty of Medicine, University of Colombo, where the study was conducted. Written informed consent was obtained from all participants. Subjects were recruited from the Endocrine Clinic of the University Obstetrics and Gynaecology Department, De Soysa Maternity Hospital, Colombo, Sri Lanka. Diagnosis of PCOS was based on the Rotterdam criteria. This is a case control study, consisting of 55 cases and 110 controls.

Recruitment of Subjects: Women whose symptoms manifested from adolescent years (11-19 years WHO), with all 3 diagnostic criteria present when aged between 16-19 years (Anovular PCOS, hyperandrogenism and polycystic ovaries on ultrasound) were recruited as cases. Women who are asymptomatic, non-androgenic, normal cycling, in whom PCOS was objectively excluded by clinical, biochemical and ultrasound assessment, were recruited as controls.

Biochemical evaluation: Serum kisspetin and testosterone levels were determined by enzyme linked immunoassay kit method (ELISA) (Phoenix Pharmaceuticals Inc., Belmond, CA and Teco Diagnostics, USA respectively) as per manufactures' recommendation.

DNA extraction and Genotyping: $2 \mathrm{ml}$ of venous blood was collected into EDTA tubes from each subject and DNA was extracted using kit method (Promega, USA) according to the manufacture's protocol. The FTO SNP rs9939609 was genotyped using tetra ARMS PCR. Primers were designed using the software primer1.soton.ac.uk/primer1.html. Following primers were used: Fout: 5'-TGG CTC TTG AAT GAA ATA GGA TTC AGA A-3'; Rout: 5'-AGC CTC TCT ACC ATC TTA TGT CCA AAC A-3' ; Fin: 5'-TAG GTT CCT TGC GAC TGC TGT GAA TAT A-3' ; Rin: 5'-GAG TAA CAG AGA CTATCC AAG TGC ATC TCA-3'. The $\mathrm{T}$ allele is detected by a $178 \mathrm{bp}$ amplicon and A allele is detected by a $201 \mathrm{bp}$ amplicon. The product size of the outer primers is $321 \mathrm{bp}$ (figure 1). Following PCR cycle conditions were used to amplify the target region; initial denaturation at $94^{\circ} \mathrm{C}$ for $5 \mathrm{~min}$, followed by 40 cycles of denaturation at $94^{\circ} \mathrm{C}$ for $30 \mathrm{~s}$, annealing at $53^{\circ} \mathrm{C}$ for 25 $\mathrm{s}$, extension at $72^{\circ} \mathrm{C}$ for $25 \mathrm{~s}$ and final extension at $72^{\circ} \mathrm{C}$ for 10 minutes. PCR products were run on ethidium bromide-stained $2 \%$ agarose gels.

Tetra ARMS PCR results were validated with high resolution melting (HRM) analysis. PCR primers for HRM analysis was designed based on the principle of competitive amplification of differentially melting amplicons (CADMA) (Borgbo et al., 2014). Following primers were used for HRM analysis; A-Allele (5'> 3') TAT GTT CAT TGC GAC TGC TGT GAA TAT A; T-allele (5'> 3') TAG GCT CCT CGC GAC TGC TGT GAA TAT T; Common Reverse (5'>3'): GAG TAA CAG AGA CTA TCC AAG TGC ATC AC. The PCR cycling conditions for HRM analysis was; initial denaturation at $95{ }^{\circ} \mathrm{C}$ for $15 \mathrm{~min}$, followed by 40 cycles of $95{ }^{\circ} \mathrm{C}$ for $15 \mathrm{~s}, 60{ }^{\circ} \mathrm{C}$ for $20 \mathrm{~s}, 72^{\circ} \mathrm{C}$ for $20 \mathrm{~s}$. HRM was performed from 65 to $95{ }^{\circ} \mathrm{C}$ with a temperature increase of $0.1{ }^{\circ} \mathrm{C} / \mathrm{s}$ with 50 acquisitions $/{ }^{\circ} \mathrm{C}$. For high resolution melt curve analysis, Precision melt analysis software version 1.2 was applied.

\subsection{Statistical Analysis}

The Kolmogorov-Smirnov test was used to test the normality of distribution. Values with a biological distribution are presented as mean \pm standard error for mean. Comparison of means between those with PCOS and controls was performed with the independent sample t test for normal values. Chi-square test was used for comparison of frequency for genotype analysis and it is also used for describing the correlation between genetic alleles with other numeric variables. All analyses were performed by SPSS software (v.18.0 SPSS, Inc., Chicago, IL). The level of significance was set as $5 \%$.

\section{Results}

Demographic, clinical and hormonal characteristics of women with PCOS and controls were summarized in Table 1. No significant difference in age, fasting blood glucose level and waist to hip ratio was observed. Women with PCOS had significantly higher BMI and $\mathrm{mFG}$ score. In addition, serum kisspeptin and testosterone 
concentrations were significantly higher in women with PCOS (kisspeptin $-4.873 \mathrm{nmol} / \mathrm{L}$; testosterone - 4.713 $\mathrm{nmol} / \mathrm{L}$ ) than controls (kisspeptin $-4.127 \mathrm{nmol} / \mathrm{L}$; testosterone $-3.415 \mathrm{nmol} / \mathrm{L} \mathrm{p}<0.05$ ).

Table1: Demographic, clinical and hormonal characteristic of subjects

\begin{tabular}{|l|l|l|l|}
\hline & PCOS & Controls & p value \\
\hline Demographic & & $33.80 \pm 0.528$ & 0.061 \\
Age (Years) & $24.67 \pm 0.883$ & & \\
Clinical & $26.89 \pm 0.716$ & $25.25 \pm 0.344$ & 0.007 \\
BMI(Kg/m2) & $8 \pm 0.445$ & $3 \pm 0.222$ & 0.006 \\
mFG score & $0.839 \pm 0.008$ & $0.824 \pm 0.004$ & 0.114 \\
WC:HC & & & \\
Biochemical & $98.81 \pm 2.08$ & $108.69 \pm 2.74$ & 0.284 \\
FBG (mg/dL) & $4.873 \pm 0.23$ & $4.127 \pm 0.132$ & 0.033 \\
Kisspeptin (nmol/L) & $4.713 \pm 0.458$ & $3.415 \pm 0.256$ & 0.018 \\
Testosterone (nmol/L) & & \\
\hline
\end{tabular}

Data are given as mean \pm standard error of the mean. mFG- modified Ferriman-Gallwey score; WC:HC - waist circumference: hip circumference; FBG- fasting blood glucose level.

Significant difference in FTO gene mutation was found with frequent association in PCOS patients when compared with control group. High frequency of A allele was observed in PCOS group. The frequency of T allele (normal allele) was significantly higher in controls (PCOS - AA $=40 \%$, AT=23.6\%, TT=36.3\%; Controls $\mathrm{AA}=13.6 \%, \mathrm{AT}=20.9 \%, \mathrm{TT}=65.4 \% ; \mathrm{p}<0.05)$. The A allele carrier genotype (AA and AT) frequencies were also significantly greater in PCOS than controls $(63.6 \%$ vs $34.5 \%$; AT and AA vs TT genotype, OR =3.32, $\mathrm{p}=0.001,95 \% \mathrm{CI}=1.69-6.52)$. Furthermore, significant correlation was found between FTO gene and BMI (chi square value $=17.05, \mathrm{p}<0.05)$.

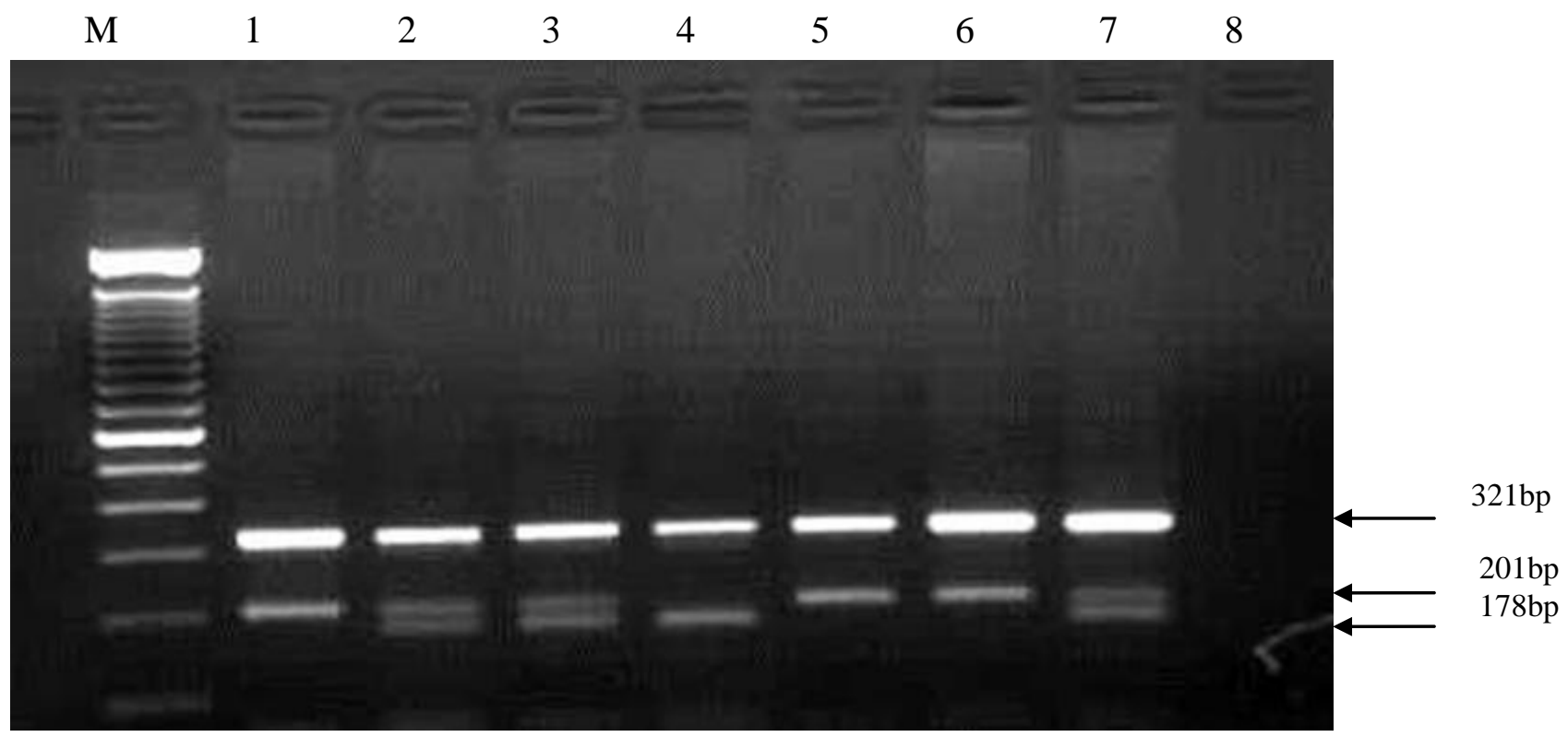

Fig (1): Detection of rs9939609 gene polymorphism by Tetra ARMS-PCR. PCR products on 2\% agarose gel. M: 100bp ladder, Lanes 1,5,6: AA genotype, lanes 2,3 7: AT genotype, lane 4: TT genotype and lane 8: negative control. 


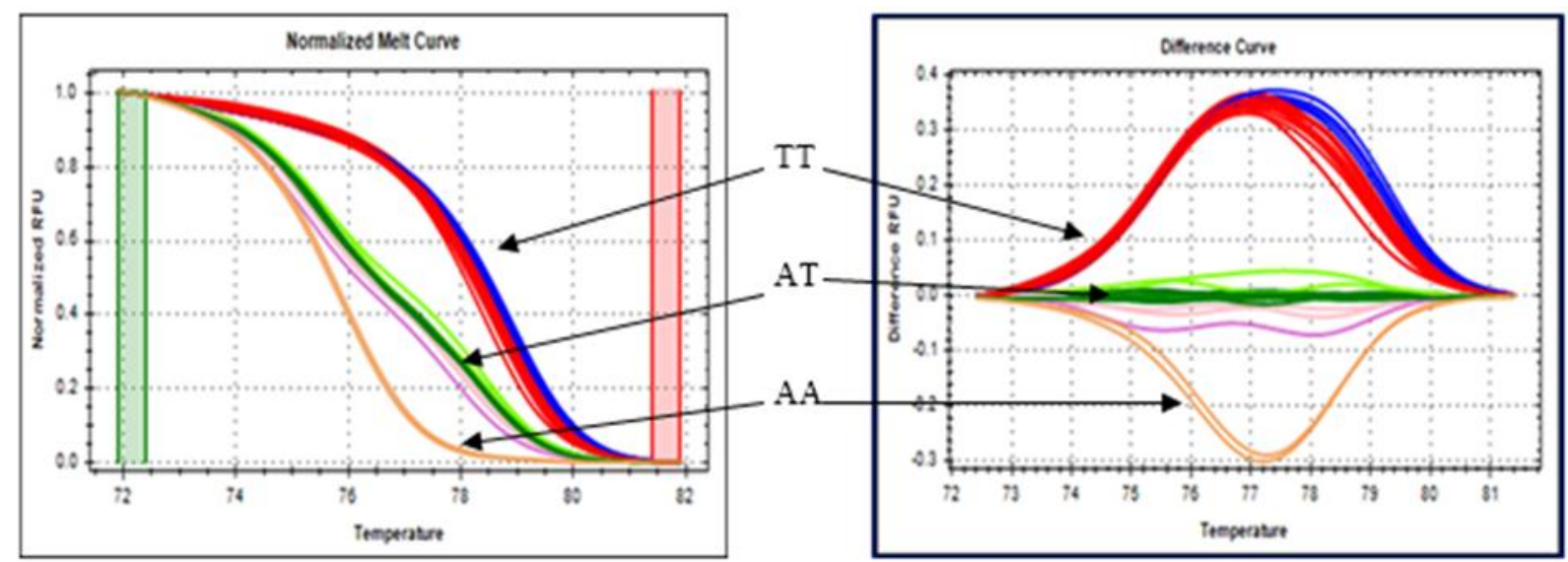

Fig (2): Detection of rs9939609 gene polymorphism by high resolution melting (HRM) analysis using both A) Normalized melt curve and B) Difference curve

\section{Discussion}

The community prevalence of PCOS ranges between $2 \%$ to $11 \%$ in various countries with ethnic diversity in its age specific prevalence (Wijeyaratne et al., 2013) and the community prevalence of PCOS in young premarital Sri Lankan women is $6.3 \%$ (Kumarapeli et al., 2008). It is reported that 40-80\% of PCOS women are overweight or obese (Barber et al., 2006 and 2008, Wher et al., 2010). Since the prevalence of obesity in PCOS is high, we can assume that genes associated with obesity might play a role in pathogenesis of PCOS. Genomewide association studies reported that FTO gene variants have an association with PCOS, mostly in Asians (Li et al., 2013). The mechanism underlying the association of the FTO gene polymorphism with PCOS risk remains unclear. However, some studies have reported that FTO gene influence PCOS mainly via the association with obesity or obesity-related parameters such as BMI (Tan et al., 2010; Yan et al., 2009; Barber et al., 2008; Wehr et al., 2010; Liu et al., 2017).

Several studies have been carried out to determine the role of FTO gene variants and PCOS susceptibility, however the results were contradictory. Study by Barber et al., (2008), Yan et al., (2009), Sokkary et al., (2014) and Farhan et al., (2015) reported an association between the FTO rs9939609 variant and PCOS, which are similar to the findings of the present study. On the other hand, studies of Tan et al., (2010), Wehr et al., (2010), Ewens et al., (2011) and Ramos et al., (2015) showed no association between SNPs in FTO and PCOS phenotype. The observed discrepancies may be due to variation in study design, sample size, demographic, ethnicity and genetic characteristics of differing study populations.

In this study, A allele (mutant allele) was more prevalent in PCOS women and T allele (normal allele) was more prevalent in control group. Furthermore, present study showed significant correlation between FTO gene polymorphism and BMI in PCOS group. This finding is consistent with former studies by Barber et al., (2008) and Farhan et al., (2015).

In conclusion, this study is the first to determine any association between FTO gene variant rs9939609 and PCOS in Sri Lankan women. Our results demonstrate that the rs9939609 variant of FTO gene is significantly associated with PCOS among Sri Lankan women, probably by its effect on BMI.

\section{Disclosure}

No conflict of interest

\section{Funding}

Study was funded by National Research Council of Sri Lanka (NRC no 15-149). 


\section{Acknowledgements}

We thank all the staff of the Professorial Obstetrics and Gynaecology Department and Professorial Unit of De Soysa Hospital for Women, Colombo for their ready assistance and support with ultrasound scanning, all staff of the Reproductive Biology and Endocrinology Laboratory, at the Department of Obstetrics and Gynecology, Faculty of Medicine and the patients and their families for their wonderful cooperation. We also thank the staff of Bank of Ceylon, Head office, Colombo for their voluntary participation for the study. We specially thank Dr. Anoma Senanayake for her excellent support during the ultrasound examinations. We also thank Dr. Sumudu Jayasinghe and Dr. Dakshila Galappathi for their excellent support in coordinating the patient evaluation and sample collections.

\section{References}

[1] A.H. Balen, G.S. Conway, G. Kaltsas, K. Techatrasak, P.J. Manning, C. West and H.S. Jacobs, "Polycystic ovary syndrome: the spectrum of the disorder in 1741 patients," Hum Reprod, vol. 10, pp. 2107-2111, 1995.

[2] A.L. Liu, H.J. Xie, H.Y. Xie, J. Liu, J. Yin, J.S. Hu and C.Y. Pen, “Association between fat mass and obesity associated (FTO) gene rs9939609 A/T polymorphism and polycystic ovary syndrome: a systematic review and metaanalysis," BMC Medical Genetics, vol. 18, pp. 89, 2017.

[3] C.N. Wijeyaratne, S.A.D. Udayangani and A.H. Balen, "Ethnic-specific polycystic ovary syndrome: epidemiology, significance and implications," Expert Rev. Endocrinol. Metab, vol. 8(1), pp. 71-79, 2013.

[4] D.A. De Luis, R. Aller, R. Conde, O. Izaola, B. De La Fuente and M.G. Sagrado, "Relation of the rs9939609 gene variant in fto with metabolic syndrome in obese female patients," Journal of Diabetes and its Complications, vol. 27(4), pp. 346-350, 2013.

[5] E. Wehr, N. Schweighofer, R. Moller, A. Giuliani, T.R. Pieber and B. Obermayer-Pietsch, "Association of FTO gene with hyperandrogenemia and metabolic parameters in women with polycystic ovary syndrome," Metabolism, vol. 59, pp. 575-580, 2010.

[6] F.J. Al-Tu'ma, N. HadiFarhan and W.G. Al-Safi, "Association between Fat Mass and Obesity Geners9939609 Polymorphism with PCOS Women in Iraqi Population,” Ijppr.Human, vol. 5(1), pp. 62-72, 2015.

[7] H.G. Osman, A.A.A. El-Refaeey, A.M.A. El-Sokkary, M.M.A El-Sokkary and R.A. El-Saeed, "A Study on Fat Mass and Obesity Associated (FTO) Gene rs9939609 Variant in Egyptian Women with Polycystic Ovarian Syndrome," Australian Journal of Basic and Applied Sciences, vol. 8(13), pp. 98-104, 2014.

[8] K.G. Ewens, M.R. Jones, W. Ankener, D.R. Stewart, M. Urbanek, A. Dunaif, R.S. Legro, A. Chua, R. Azziz and R.S. Spielman, "Type 2 diabetes susceptibility single-nucleotide polymorphisms are not associated with polycystic ovary syndrome," Fertility and Sterility, vol. 95(8), pp. 2538-2541, 2011.

[9] Q. Yan, J. Hong, W. Gu, Y. Zhang, Q. Liu, Y. Su, X. Li, B. Cui and G. Ning, “Association of the common rs9939609 variant of fto gene with polycystic ovary syndrome in Chinese women," Endocrine, vol. 36(3), pp. 377-382, 2009.

[10] R.B. Ramos and P.M. Spritzer, "FTO gene variants are not associated with polycystic ovary syndrome in women from Southern Brazi," Gene, vol. 560, pp. 25-29, 2015.

[11] S. Tan, A. Scherag, O.E. Janssen, S. Hahn, H. Lahner, T. Dietz, S. Scherag, H. Grallert, C.I.G. Vogel, R. Kimmig, T. Illig, K. Mann, J. Hebebrand and A. Hinney, "Large effects on body mass index and insulin resistance of fat mass and obesity associated gene (FTO) variants in patients with polycystic ovary syndrome (PCOS)," BMC Medical Genetics, vol. 11, pp. 12, 2010.

[12] T. Borgbo, L.S. Kristensen, I. Lindgren, C.Y. Andersen and L.L. Hansen, "Genotyping common FSHR polymorphisms based on competitive amplification of differentially melting amplicons (CADMA)," J Assist Reprod Genet, vol. 31, pp. 1427-1436, 2014. 
[13] T. Li, K. Wu, L. You, X. Xing, P. Wang, L. Cui, H. Liu, Y. Cui, Y. Bian, Y. Ning, H. Zhao, R. Tang and Z.J. Chen, "Common variant rs9939609 in gene FTO confers risk to polycystic ovary syndrome," PLoS One, vol. 8, pp. e66250, 2013.

[14] T.M. Barber, A.J. Bennett, C.J. Groves, U. Sovio, A. Ruokonen, H. Martikainen, A. Pouta, A.L. Hartikainen, P. Elliott, C.M. Lindgren, R.M Freathy, K. Koch, W.H. Ouwehand, F. Karpe, G.S. Conway, J.A. Wass, M.R. Järvelin, S. Franks and M.I. McCarthy, "Association of variants in the fat mass and obesity associated (FTO) gene with polycystic ovary syndrome,” Diabetologia, vol. 51(7), pp. 1153-1158, 2008.

[15] T.M. Barber, M.I. McCarthy, J.A. Wass and S. Franks, "Obesity and polycystic ovary syndrome," ClinEndocrinol, vol. 65(2), pp. 137-145, 2006.

[16] T.M. Frayling, N.J. Timpson, M.N. Weedon, E. Zeggini, R.M. Freathy, C.M. Lindgren, J.R. Perry, K.S. Elliott, H. Lango, N.W. Rayner, B. Shields, L.W. Harries, J.C. Barrett, S. Ellard, C.J. Groves, B. Knight, A.M. Patch, A.R. Ness, S. Ebrahim, D.A. Lawlor, S.M. Ring, Y. Ben-Shlomo, M.R. Jarvelin, U. Sovio, A.J. Bennett, D. Melzer, L. Ferrucci, R.J. Loos, I. Barroso, N.J. Wareham, F. Karpe, K.R. Owen, L.R. Cardon, M. Walker, G.A. Hitman, C.N. Palmer, A.S. Doney, A.D. Morris, G.D. Smith, A.T. Hattersley and M.I. McCarthy, "A common variant in the FTO gene is associated with body mass index and predisposes to childhood and adult obesity," Science, vol. 316, pp. 889-894, 2007.

[17] V. Kumarapeli, R. DE. A. Seneviratne, C.N. Wijeyaratne, R.M. Yapa and S.H. Dodampahala, "A simple screening approach for assessing community prevalence and phenotype of polycystic ovary syndrome in a semi-urban population in Sri Lanka," American journal of epidemiology, vol. 168(3): pp. 321-328, 2008. 